\title{
Recepción temprana de los motetes de Tomás Luis de Victoria (ca. 1548-1611) en territorio germánico ${ }^{1}$
}

\author{
The Early Reception of the Motets of \\ Tomás Luis de Victoria (ca. 1548-1611) \\ in Germanic Territory
}

Numerosos testimonios documentan una presencia significativa de motetes de Tomás Luis deVictoria en territorio germánico a finales del siglo XVI. Junto a un importante número de fuentes conservadas en los archivos alemanes, sobresale la publicación en la zona de sus Cantiones sacrae (Dillingen, 1589), único impreso de Victoria publicado fuera de España e Italia en vida del compositor. En claro contraste con este escenario, los estudios dedicados a la recepción de la obra del abulense al norte de los Alpes son muy escasos. El resultado es un panorama repleto de lagunas. A través del examen de fuentes de naturaleza diversa, este artículo pretende arrojar luz sobre algunos aspectos del caso, identificando y comentando los testimonios más tempranos de dicha recepción.

Palabras clave:Tomás Luis deVictoria, Alemania, motete, recepción, circulación, fuentes, impresos.

Numerous testimonies document a significant presence of Tomás Luis de Victoria's motets in Germanic territory at the end of the sixteenth century. Together with an extensive number of sources preserved in German archives, of particular note is the publication of his Cantiones sacrae (Dillingen, 1589) in this region, the only work by Victoria published outside Spain or Italy during the composer's lifetime. In stark contrast, studies about the reception of the composer's works north of the Alps are very scarce. The result is a picture full of gaps. By examining sources of a diverse nature, this article aims to shed light on certain aspects of this case. In particular, it will focus on identifying and discussing the earliest testimonies of the reception of these motets.

Keywords: Tomás Luis de Victoria, Germany, motet, reception, circulation, sources, printed music.

“¿Cuál es esa obra? Las canciones sagradas de Tomás Luis deVictoria, al que, a juicio de los que aprecian con entendimiento el arte de la música, hay que contar entre los principales maestros de canto de esta época"'. Con estas elogiosas palabras se refería al compositor uno de sus coetáneos. Proceden de la dedicatoria que abre la colección de motetes del abulense

\footnotetext{
${ }^{1}$ Deseo expresar mi gratitud a Alfonso de Vicente y a Juan Ruiz Jiménez por haber leído y comentado una primera versión de este artículo.

2 "Quid autem illud? Cantiones sacrae Thomae Ludovici a Victoria, quem in principibus huius aetatis canendi magistris numerandum existimant ii, qui rerum musicarum non imperiti sunt aestimatores".
} 
publicada en 1589 en la ciudad bávara de Dillingen, las Cantiones sacrae, reedición de los Motecta (Roma, 1583) publicados años antes por Antonio Gardano. La dedicatoria fue escrita por Johann Mayer, el impresor de la colección, y está dirigida al por entonces deán de la catedral de Augsburgo, Johann Otto von Gemmingen (1545-1598) ${ }^{3}$. El pasaje citado cierra un breve comentario sobre el proceso de elección del repertorio objeto de la publicación. Según nos cuenta Mayer, quien unos años antes ya había dedicado un primer libro a Gemmingen, le había sido difícil encontrar material dotado de la calidad debida a la categoría del deán ${ }^{4}$, pero, tras larga búsqueda, por fin logró dar con una obra que cumplía con el requisito: los motetes deVictoria, un compositor al que, según los entendidos, debía incluirse entre los más destacados de la época.

A pesar del probable fin comercial de las palabras de Mayer, el valor de su testimonio está fuera de toda duda. No solo demuestra que la fama del compositor trascendía los ámbitos romano e hispánico a los que su música se suele vincular, sino que documenta la gran consideración que algunos tenían de él en el contexto germánico ${ }^{5}$. La especial vinculación deVictoria con este contexto es de sobra conocida ${ }^{6}$, y se suele fundamentar en la dilatada actividad del compositor en el Colegium Germanicum de Roma, institución de la que primero fue alumno y después maestro, y así como en que dedicara varias de sus colecciones impresas a figuras prominentes de la escena político-religiosa alemana. En especial, la dedicatoria de su primer libro de motetes al cardenal y obispo de Augsburgo, Otto Truchsess von Waldburg, suscitó especulaciones ya en los estudios más tempranos dedicados al compositor ${ }^{7}$. Más recientemente, el trabajo de catalogación de Eugene Cramer ha puesto en evidencia la

Tomás Luis de Victoria: Cantiones sacrae (Dillingen, 1589), carta dedicatoria escrita por el impresor Johann Mayer. Traducción castellana tomada de Luis González Platón: "Traducción de las dedicatorias latinas", Tomás Luis de Victoria, pasión por la música, Ana Sabe Andreu (aut.), Ávila, Institución Gran Duque de Alba de la Diputación de Ávila, 2008, p. 223.

${ }^{3}$ Peter Rummel: "Gemmingen, Johann Otto von (1545-1598)", Die Bischöfe des Heiligen Römischen Reiches. 1448 bis 1648. Ein biographisches Lexikon, Erwin Gatz (ed.), Berlín, Duncker \& Humblot, 1996, pp. 216-217.

${ }^{4}$ El primer libro que Mayer dedicó a Gemmingen es una crónica de las experiencias de la Compañía de Jesús tras su llegada a Japón en 1582. Se trata de Jüngste Zeytung auß der Weitberümbten Insel Jappon: Was in derselben nechst verschinen 1582 Jar. vor der Societet Jesv... (Dillingen, 1586). Véase Otto Bücher: Bibliographie der deutschen Drucke des XVI. Jahrhunderts, Viena et al., Walter Krieg, 1960, p. 218.

5 Samuel Rubio: "Historia de las reediciones de los motetes de T. L. de Victoria y significado de las variantes introducidas en ellas", Samuel Rubio (1912-2012). In memoriam. Estudios sobre Tomás Luis de Victoria, José Sierra Pérez (ed.), pp. 103-104. Véase también Ana Sabe Andreu: Tomás Luis de Victoria..., p. 156.

${ }^{6}$ Véase por ejemplo Higinio Anglés: "Austausch deutscher und spanischer Musiker im 15. und 16. Jahrhundert”, Scripta musicologica, José López-Calo (ed.), Roma, Edizioni di Storia e Letteratura, 1975, vol. 2, pp. 697-699

${ }^{7}$ Una síntesis de las mismas en Daniele V. Filippi: Tomás Luis de Victoria, Palermo, L'Epos, 2008, pp. 32-33. Victoria también dedicó su Liber primus qui missas... (Venecia, 1576) a una autoridad eclesiástica germánica, el arzobispo de Colonia, Ernst von Bayern. 
existencia de un importante número de fuentes que demuestran que la mencionada vinculación fue más allá del ámbito de los lazos personales. Además de varios ejemplares de impresos de Victoria, los archivos alemanes conservan una quincena de manuscritos copiados entre finales del siglo XVI y principios del XVII que incluyen obras del compositor, básicamente motetes $^{8}$. El fenómeno de circulación que este conjunto de fuentes documenta adquiere relevancia a la luz de la reedición de Dillingen de 1589, así como por la inclusión de motetes sueltos del abulense en antologías publicadas entre 1594-1622 en Colonia, Múnich, Leipzig y Estrasburgo9.

Con todo, el fenómeno de circulación de la música de Victoria en territorios de habla germánica sufre de un sorprendente vacío historiográfico. El interés del panorama descrito contrasta con un estado de la cuestión afectado por importantes lagunas, pues los estudios sobre aspectos particulares de la circulación de la obra de Victoria en dicho territorio son más bien escasos ${ }^{10}$. Faltan trabajos sobre fuentes individuales y contribuciones que documenten posibles contextos de interpretación. En suma, estudios que doten de narratividad histórica a la labor de catalogación realizada. De las fuentes conservadas se coligen dos hechos incontestables: que la recepción de Victoria en la zona existió y que el género motete gozó en ella de una posición privilegiada. El resto son todo incógnitas. ¿Cuándo empezó dicha recepción y a través de qué canales se hizo posible? ¿Qué centros incorporaron música de Victoria y qué suscitó su interés por la misma? ¿Es el predominio del motete en las fuentes fruto de la casualidad, es decir, de la arbitrariedad en la conservación de las propias fuentes? De lo contrario, ¿a qué responde? En la medida que semejantes cuestiones sigan sin recibir respuesta, estaremos lejos de adquirir una panorámica adecuada del caso. Lejos de ser capaces de contextualizar el testimonio de Mayer arriba citado.

\footnotetext{
${ }^{8}$ Eugene C. Cramer: Tomás Luis de Victoria. A Guide to Research, Nueva York y Londres, Garland, 1998, pp. 23-30 y 47-88. Entre las fuentes figura un número importante de tablaturas para órgano, que no serán tratadas aquí por quedar fuera del marco cronológico que nos disponemos a abordar, pero que ponen de manifiesto la importancia del género motete en el fenómeno de recepción de Victoria en territorio germánico. Un listado de las mismas en Andrés Cea Galán: "Cantar Victoria al órgano: Documentos, Música, Praxis”, Estudios. Tomás Luis de Victoria. Studies, Javier Suárez-Pajares, Manuel del Sol (eds.), Madrid, ICCMU, 2013, pp. 328-333.

${ }_{9}$ Para información detallada sobre las antologías, véase E. Cramer: Tomás Luis..., pp. 43-45 y D. Filippi: Tomás Luis..., p. 180.

10 Que sepamos, se reducen a Ángel Manuel Olmos: "Las obras de Tomás Luis de Victoria en la tablatura para órgano de Pelplin (Polonia) 'Biblioteka seminarium, 304-8, 308 a' (1620-1630)", Cinco siglos de música de tecla española: actas de los Symposia FIMTE 2002-2004, Luisa Morales (ed.), Almería, Asociación Cultural LEAL, 2007, pp. 87-124; Adriano Giardina: "Who Wrote the Second Ave maris stella of Tomás Luis de Victoria?", Estudios. Tomás Luis de Victoria..., pp. 115-126 y Stephanie Klauk: "Problems of Authenticity in the Works of Tomás Luis de Victoria. Some Methodological Considerations", New Perspectives on Early Iberian Music, Tess Knighton, Emilio Ros-Fábregas (eds.), Kassel, Reichenberger, 2015, pp. 56-68.
} 
El objetivo de este artículo es abordar algunas de las cuestiones planteadas a través del examen de testimonios históricos de naturaleza diversa. En concreto, nos interesaremos por documentar los signos más tempranos de la circulación de los motetes de Victoria en territorio germánico. Muchos de tales testimonios no han recibido atención alguna, cuanto menos en relación aVictoria; otros no han sido estudiados con el detalle que merecen. Nuestro recorrido comenzará con un comentario sobre la publicación de las Cantiones sacrae, único impreso de Victoria publicado fuera de España e Italia en vida del compositor, y el testimonio más llamativo de dicha circulación. El acontecimiento determina el marco cronológico de nuestra aportación y algunos de sus interrogantes principales. A continuación nos ocuparemos de un ceremonial coetáneo que permitirá un acercamiento al mismo fenómeno desde un ángulo distinto. Las observaciones que se derivan del estudio de ambos testimonios evidenciarán el interés de atender a las fuentes prácticas más tempranas con música de Victoria conservadas en archivos alemanes, ejercicio al que dedicaremos la parte final del trabajo.

El impreso de Dillingen se ha citado en numerosos estudios desde que en 1834-35 Francois-Joseph Fétis lo mencionó en su Biographie universelle des musiciens ${ }^{11}$, aunque, ajeno a los contextos italiano e hispánico en que se suelen centrar los estudios dedicados aVictoria, no se ha tratado con el detalle que merece ${ }^{12}$.Varios aspectos confieren a la publicación un especial interés historiográfico. Por lo pronto, nos proporciona el dato fehaciente de que en 1589, como muy tarde,Victoria entró a formar parte del mercado germánico de música impresa. Así lo confirma, no ya el hecho de la publicación, sino un dato relativo a la distribución del impreso que hasta la fecha ha permanecido inédito: su presencia documentada en la feria del libro de Frankfurt el mismo año de la publicación. Las Cantiones sacrae figuran, en efecto, en el catálogo que recoge las novedades de la primera edición semestral de la feria de 1589 (véase Ilustración 1) ${ }^{13}$. El impreso es uno de los doce títulos que conforman la sección de libros de "Música en diversas lenguas". Cabe mencionar que el responsable del catálogo, el próspero

\footnotetext{
${ }^{11}$ Francois-Joseph Fétis: Biographie universelle des musiciens et bibliographie générale de la musique, París, Firmin Didot, 1834-35, vol. 8, p. 341.

12 Hasta donde sabemos, el único trabajo que se ocupa específicamente de la publicación de Dillingen, aunque solo parcialmente y de forma breve, es Iain Fenlon: "From Print to Public: The Milanese and Dillingen Editions of Victoria's Motets”, Estudios. Tomás Luis de Victoria..., pp. 27-36.

${ }^{13}$ Georg Willer: Catalogus novus nundinarum vernalium Francofurti ad Moenum anno M.D.LXXXIX. Celebratarum quibus accesserunt vetustiores nonnulli, willerianis tamen catalogis antea non inserti. Annum impreßionis numerus singulis praepositus demonstrat. Plerique in aedibus Georgii Willeri civis et bibliopolae Augustani, venales habentur. Verzeichnu $\S$ fast aller neuwer Buecher welche seyther der nechstverschienen Herbstme $\beta$ bi $\Omega$ auff diese gegenwertige Fastenme $\beta$ in offentlichem Druck seyn außgangen (Nikolaum Basseum, Frankfurt am Main, 1589), f. E3V . Edición facsímil en Bernhard Fabian (ed.): Die Messkataloge des sechzehnten Jahrhunderts. Die Messkataloge Georg Willers, Hildersheim y Nueva York, Georg Olms, 1978, vol. 4, p. 152.
} 
librero de Augsburgo Georg Willer (1514-1593/94), fue un colaborador habitual de la imprenta Mayer. En ocasiones asumía el papel de editor y, más a menudo, se ocupaba de la distribución de las publicaciones que salían de las prensas de Dillingen, gran parte de cuyas tiradas solía vender en la feria de Frankfurt ${ }^{14}$. Así que es posible que también fuera el caso del impreso de Victoria.

La celebración de una feria en Frankfurt se ha podido documentar desde ca. 1240. Durante el siglo XV, y en correspondencia con la consolidación de la imprenta, el libro incrementó su relevancia relativa entre los bienes con que allí se comerciaba hasta que, en las últimas décadas del siglo, la sección dedicada al mismo se había convertido en un evento de carácter internacional al que asistían todo tipo de profesionales. Impresores y editores acudían para ofrecer su producción a libreros y coleccionistas, pero también para comprar al por mayor el material necesario para su actividad ${ }^{16}$. Desde el punto de vista de la circulación musical, así, la presencia del impreso deVictoria es del mayor interés, pues sitúa a los motetes del abulense en uno de los principales centros de distribución de la época. Relevante en aras de documentar la circulación de este repertorio, el dato no agota el atractivo historiográfico de las
Quinq; vocibus compofita, Authore loachimo Friderico Frizio Kapfienbergenfium fcholx Rectore. Grecij excudebat Georgius VVidmanftadius.

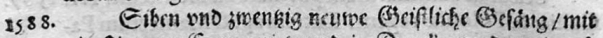
vicr ftimmon Componire wuth in Drudt veroronet / ourch Tohannem Etcurtin Schmalkaldenfem / Etattfchreıber

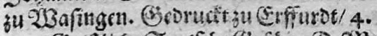
bic firnombfic Iefi vind fonffen a fingen/auch allerlen Ins firumentet jugebrauslien / mit finffi vno fechs Etimmen Eomponir//Ourch Beorgium Dutfionem Surtfi. Sorffichen

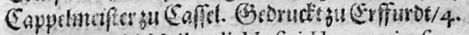

3s s8. D. Tacobi Mailandi Mufici Harmonix facre quinq; vocum felectxac compofitione diuina, noux prorfus editionc. Erfurdia, 4 .

Thomx Ludonicià Vißtoria, Abulenfis Mnficifuauifimi Cantiones, quatuor, quinque, fex, octo \& ducdecim vocum, nunquam ante hacin Germania excufę. Dilinga cxcudebat Ioannes Mayer.4.

1588. Dascrfe Budf neumer/lufiger nno boffitidjer / melta ni Megapolitani \& c. Selmffatt. Bionctit Durch Jacobum. Suciün.

1589. Ficume furforeilige Teuffche Siedein mit orenen ourch Jrank Joachim Sorechtl. Gooructi ju Purnberg/ Durch Batfarinam 3 erlacţin.

1599. Liber fecundus gemmæ Muficalis, felectifsimas varij filicantiones, qux Madrigali \& NapolitaneItalis dicuntur,quatuor,quinq;, fex \& pluriuni vocum, continen \&c. Noriberge ex typographia Katharinz Gerlachix. Pfalmus

Ilustración 1. Las Cantiones sacrae de Victoria recogidas en el catálogo de la primera edición semestral de la feria del libro de Frankfurt de 158915

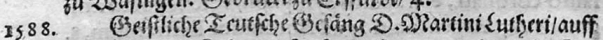
licticr sicocr mit vict vilo fünff Etimmen Thoma ManciEtimmen/nacls artoer 23 ilfchen Villanellen componirt,

\footnotetext{
${ }^{14}$ Otto Bucher: "Sebald Mayer, der erste Dillinger Buchdrucker (1550-1576)", Jahrbuch der historischen Vereins Dillingen, 54, 1952-53, p. 118. Para ejemplos concretos de colaboración entre Georg Willer y la imprenta Mayer, véase Hans-Jörg Künast: "Die Akademische Druckerei der Universität Dillingen”, Die Universität Dillingen und ihre Nachfolger. Stationen und Aspekte einer Hochschule in Schwaben. Festschrift zum 450 jährigen Gründungsjubiläum, Rolf Kießling (ed.), Dillingen, Historischer Verein Dillingen an der Donau, 1999 (Jahrbuch des Historischen Vereins Dillingen an der Donau, vol. 100), pp. 602-604.

${ }^{15}$ Imagen digitalizada y facilitada por la Universitäts- und Landesbibliothek Halle: http://nbn-resolving.de/urn:nbn:de:gbv:3:1-493644 (última consulta: 29-10-2015).

${ }_{16}$ Graham Pollard: "The German Book Fair Catalogues", The Distribution of Books by Catalogue. From the Invention of Printing to A. D. 1800, G. Pollards, A. Ehrman (eds.), Cambridge, Roxburghe Club, 1965, pp. $70-72$
} 
Cantiones sacrae. El evento es igualmente valioso porque implica una constelación de interrogantes que, al dotar de forma concreta las lagunas que afectan al caso que nos ocupa, representan un excelente punto de arranque para la labor del historiador.

Una de las preguntas que suscita la publicación de Dillingen resulta de especial interés para nuestro propósito: ¡cómo explicar la aparición de un impreso de motetes de Victoria en una región en la que, hasta donde sabemos, el compositor nunca estuvo activo? El interés de atender a esta cuestión se hace evidente a la luz del repertorio impreso habitual en el sur del territorio germánico durante la época, pues, aunque existieron, las monografias dedicadas a compositores no germánicos no fueron algo frecuente, menos aún en el ámbito de la música sacra. Es cierto que algunos impresores de ciudades importantes publicaron libros de polifonía de autores activos en Venecia y Roma, impulsando de este modo la difusión de la música italiana en suelo germánico ${ }^{17}$. Pero representan una proporción muy pequeña respecto del total. La presencia a finales de siglo XVI en la producción impresa al norte de los Alpes de compositores que, como Victoria, estuvieron activos en Italia se debió sobre todo a su aparición en antologías ${ }^{18}$. El formato monográfico, en cambio, como la mayor parte de dicha producción en la época de la publicación de las Cantiones sacrae, se nutrió principalmente de compositores activos en la zona. El que entre ellos se contaran algunos extranjeros justificaría una parte importante de las monografias dedicadas a autores no germánicos entonces publicadas. El caso de Augsburgo resulta ilustrativo: durante la segunda mitad del siglo XVI y en las primeras décadas del XVII, la producción de sus imprentas musicales prácticamente se limitó a los compositores que dirigían las capillas de música de las instituciones eclesiásticas de la ciudad $^{19}$. Si entre las monografias allí aparecidas durante este período hallamos algunas dedicadas a autores no germánicos, se trata de compositores que estaban activos en algún centro de la región. Es el caso de las colecciones de motetes publicadas por el impresor Philipp Ulhart: las Cantiones sacrae de Manfredo Barbarini Lupus (Augsburgo,

\footnotetext{
${ }^{17}$ Entre ellos destacan Nikolaus Stein, en Frankfurt, y Paul Kauffmann, en Núremberg. Veáse Theodor Wohnhaas: "Stein, Nikolaus", Die Musik in Geschichte und Gegenwart. Allgemeine Enzyklopädie der Musik, $2^{a}$ ed., Ludwig Finscher (ed.), Kassel, Bärenreiter, 1994-2007 [=MGG²], Personenteil, vol. 15, cols. 1390-1391 y Thomas Röder: "Kauffmann, Paul", $M G G^{2}$, Personenteil, vol. 9, cols. 1555-56.

${ }^{18}$ En ocasiones, la inclusión de música de un compositor en repetidas antologías daba paso a la publicación de alguna monografía, de lo que se deduce una cierta estrategia en términos de preparación de un mercado por parte del editor. Sobre el particular, véase Susan Lewis Hammond: Editing Music in Early Modern Germany, Burlington, Ashgate, 2007.

19 Thomas Röder, Theodor Wohnhaas: "Der Augsburger Musikdruck von den Anfängen bis zum Ende des Dreißigjährigen Krieges", Augsburger Buchdruck und Verlagswesen. Von den Anfängen bis zur Gegenwart, Helmut Gier y Johannes Janota (eds.), Wiesbaden, Otto Harrassowitz Verlag, 1996, pp. 310-11 y 317.
} 
1560) y tres libros de Cantiones sacrae de Johannes de Cleve (Augsburgo, 1560-1579 $)^{20}$. El ejemplo de Dillingen, sin duda más representativo para el caso que nos ocupa, es igualmente paradigmático: al margen del impreso de Victoria, la única monografía allí publicada dedicada a un compositor no germánico fue el primer libro de Magnificat de Giovanni Martino Cesare (ca.1590-1667), quien, aunque oriundo del norte de Italia, estuvo activo en la actual Austria, hallándose en el año de la aparición del impreso en Grünzburg, población cercana a Dillingen, al servicio de Carlos de Austria, Margrave de Burgau (1560-1618) 21.

La proximidad parece un parámetro fundamental en la conformación de la lista de compositores cuyas obras fueron publicadas en forma de monografía en las imprentas del sur de Alemania. ¿Cómo dar cuenta, pues, del caso de Victoria? Durante el tiempo que permaneció vinculado al Colegium Germanicum, una parte importante de cuyo alumnado estaba formado por jóvenes de origen germánico que tras los estudios regresaban a su tierra natal, el abulense tuvo la oportunidad de cultivar relaciones que, años más tarde, pudieran facilitar un contacto con Johann Mayer, por lo que, desde el punto de vista del acceso, nada impediría suponer que el propio compositor impulsara la publicación ${ }^{22}$. Pero lo cierto es que carecemos de cualquier indicio que respalde esta tesis o que apunte de algún modo a la implicación deVictoria en el proyecto. Los datos conocidos de la vida del compositor durante los años anteriores no revelan pista alguna que sugieran su participación en el mismo ${ }^{23}$. Desde septiembre de 1587 ocupaba el cargo de capellán de la Emperatriz María de Austria en el Monasterio de las Descalzas Reales, en Madrid, y no existe rastro documental que indique que entre 1587 y 1589 abandonara España o que se produjera un intercambio epistolar con Johann Mayer o su entorno ${ }^{24}$. Con todo, es

\footnotetext{
20 Oriundo de Italia, Barbarini Lupus estuvo básicamente activo en centros de la actual Suiza. Arnold Geering: "Barbarini Lupus, Manfred", The New Grove Dictionary of Music and Musicians, 2. ' ed., Stanley Sadie (ed.), Londres, Mcmillan, 2001 [=NG ${ }^{2}$ ], vol. 2, pp. 685-686. De origen neerlandés, por su lado, de Cleve (ca. 1528-1582) fue maestro de capilla de Carlos II de Estiria en Graz. Albert Dunning: "Cleve, Johannes de", -, vol. 6, pp. 51-52.

${ }^{21}$ Se trata de Magnificat item Antiphonae Mariales... Liber primus (Dillingen, 1611). Véase Otto Bucher: "Adam Meltzer (1603-1610) und Gregor Hänlin (1610-1617) als Musikaliendrucker in Dillingen/Donau”, Gutenberg-Jahrbuch, 1956, pp. 222-223. Para la actividad documentada del compositor, Lindsey Kirwan y Steven Saunders: "Cesare, Giovanni Martino", NG², vol. 5, p. 390.

22 Sobre el alumnado del Colegium Germanicum, véase Thomas D. Culley: Jesuits and Music: A Study of the Musicians Connected with the German College in Rome During the 17th Century and of their Activities in Northern Europe, Roma, Instituto Histórico Jesuita, 1970, p. 17.

${ }^{23}$ El estado de la cuestión más reciente sobre la biografía de Victoria se puede consultar en D. Filippi: Tomás Luis..., pp. 21-51. Para una lista actualizada de los documentos conservados de los años anteriores a la publicación de Dillingen, Alfonso de Vicente: Tomás Luis de Victoria. Cartas (1582-1606), Madrid, Fundación Caja Madrid, 2008, pp. 38-39.

${ }^{24}$ Victoria siguió uno u otro procedimiento en proyectos de publicación posteriores. Por ejemplo, viajó a Roma en 1592 con ocasión de la publicación de su segundo libro de misas, cuya dedicatoria firma
} 
necesario admitir que los datos documentados de la biografia de Victoria durante este periodo no son precisamente prolijos: al margen de una carta dirigida al deán de la catedral de Jaén, escrita y firmada por Victoria en Madrid en marzo de 1588, se reducen a tres referencias archivísticas que no permiten más que suponer, y solo con una estimación cronológica aproximada, el paradero del compositor ${ }^{25}$. En cambio, algunas características de la propia colección y los datos disponibles sobre su recepción sí respaldan de forma activa la ausencia de todo vínculo entre el abulense y el proyecto.

Diversos estudios han puesto de relieve la especial diligencia de Victoria para con el proceso de edición de sus libros, tanto por lo que se refiere a los aspectos formales, como a los criterios de ordenación del contenido y los detalles musicales del mismo ${ }^{26}$. En este sentido, las Cantiones sacrae presentan algunas características que alejan a la publicación de los hábitos del abulense. La más evidente es la ausencia de un prefacio o una dedicatoria escritos por el propio compositor ${ }^{27}$. Uno u otra se hallan invariablemente en los impresos para los que su implicación personal está documentada, no siendo así en aquellas publicaciones para las que no se han hallado indicios de su participación, todas ellas reediciones de colecciones anteriores: además de la publicación alemana, se trata de los Motecta de 1589 y 1603, reediciones del libro de motetes de 1583, y de los Hymni de 1600, reedición de la colección de himnos de 1581. Común a los cuatro impresos es también el hecho de que no se conserve un solo ejemplar en España, donde su recepción ni siquiera se ha podido documentar ${ }^{28}$. Existe constancia de queVictoria tomaba parte activa en el proceso de distribución de sus libros impresos, que él mismo ofrecía a instituciones eclesiásticas o a

el compositor estando en dicha ciudad. El procedimiento epistolar fue el seguido en el proyecto de publicación, nunca finalizado, de los salmos conservados en el Manuscrito musicale 130 de la Biblioteca Nazionale Centrale Vittorio Manuele II de Roma. Véase Esteban Hernández Castelló (ed.): Tomás Luis de Victoria. Salmos de Vísperas. Manuscrito Musical 130 de la Biblioteca Nazionale Vittorio Emanuele II di Roma, Ávila, Obra social de Caja de Ávila, 2003, pp. 14-15.

${ }^{25}$ A. de Vicente: Tomás Luis..., pp. 38-39. Conservadas en las catedrales de Toledo, Plasencia y Las Palmas, y con fecha de setiembre y diciembre de 1588 y agosto de 1589, respectivamente, las referencias registran la decisión de los respectivos cabildos de gratificar económicamente a Victoria por la adquisición de ejemplares de algunas de sus publicaciones. Los testimonios permiten, a lo sumo, suponer que Victoria remitió personalmente los libros desde Madrid, pero no identifican las fechas de envío.

26 S. Rubio: "Historia de las reediciones..."; Adriano Giardina: "Tomás Luis de Victoria: Le premier livre de motets, organisation et style", tesis doctoral, Universidad de Ginebra, 2009, pp. 66-87; Martin Ham: "Victoria as Self-Editor. Changing Musical Texts and their Implications", Estudios. Tomás Luis de Victoria..., pp. 277-306; Juan Ruiz Jiménez: "Recepción y pervivencia de la obra de Victoria en las instituciones eclesiásticas de la Corona de Castilla", Tomás Luis de Victoria y la cultura musical en la España de Felipe III, Alfonso de Vicente, Pilar Tomás (dirs.), Madrid, Centro de Estudios Europa Hispánica, 2012, pp. 305-307; D. Filippi: "Carlo Borromeo and Tomás Luis de Victoria: a Gift, Two Letters and a Recruiting Campaign”, Early Music, XLIII/1, 2015, pp. 45-46.

${ }^{27}$ La colección cuenta con una dedicatoria a la Virgen firmada por Victoria, pero se trata de la dedicatoria de la edición de 1583, que Mayer recogió en la reedición.

28 J. Ruiz: "Recepción y pervivencia...", p. 317. 
personalidades siguiendo un modelo que se ha venido a denominar "donación remunerada": el abulense remitía las colecciones con la esperanza de recibir una cierta cuantía de dinero con la que recuperar los costes de la publicación y, claro está, con el fin de que sus obras fueran integradas en el canon musical del centro correspondiente ${ }^{29}$.Varias cartas conservadas en archivos españoles demuestran que, tras su regreso de Roma en ca.1585, el compositor se preocupó por difundir sus obras por la Península Ibérica ${ }^{30}$. El que no se haya hallado rastro alguno de la recepción en el territorio peninsular de algunos de sus impresos sugiere que Victoria no tomó parte en la distribución, respaldando la hipótesis de que no participó en los respectivos proyectos.

Resulta igualmente significativo que las obras incluidas en las Cantiones sacrae no presenten variantes musicales respecto a publicaciones anteriores ${ }^{31}$. Es un rasgo que la colección comparte con los Motecta de 1589 y 1603 y que, de nuevo, contrasta con el proceder documentado del compositor. El cuidado del maestro abulense para con el contenido musical de sus libros se pone especialmente de manifiesto en las repetidas revisiones de que fueron objeto aquellos motetes publicados en más de una ocasión -en algunos casos, como las antífonas marianas Ave regina coelorum y Regina coeli, las piezas aparecieron hasta cuatro veces antes de $1589^{32}$ - El resultado de las revisiones son pequeñas modificaciones que afectan tanto a la disposición del texto, como a las alteraciones y a fragmentos melódicos en una o varias voces ${ }^{33}$. Modificaciones que, en el caso de las Cantiones sacrae, no se dan, lo que confiere a la edición carácter de estricta reimpresión, un concepto ajeno al historial de publicaciones de Victoria hasta 1589.

Como han observado autores anteriores, la aparente desvinculación de Victoria respecto al proyecto de impresión de las Cantiones sacrae despoja a

29 Juan Ruiz: La Librería de Canto de Órgano: creación y pervivencia del repertorio del Renacimiento en la actividad musical de la catedral de Sevilla, Sevilla, Junta de Andalucía, Consejería de Cultura, 2007, pp. 143-144; J. Ruiz: "Recepción y pervivencia...", p. 304.

30 Para las distintas hipótesis sobre la fecha de regreso de Victoria a España, véase D. V. Filippi: Tomás Luis..., pp. 43-44. Las cartas se pueden consultar en A. de Vicente: Tomás Luis..., pp. 68, 72, 84 y 90.

${ }^{31} \mathrm{Al}$ contrario de lo que se colige de los aparatos críticos, repletos de errores, de Higinio Anglés (ed.): Tomás Luis de Victoria. Opera omnia. Vol. 2: Motetes I-XXI, Barcelona, Consejo Superior de Investigaciones Científicas, 1965 (Monumentos de la Música Española XXVI), pp. 30-39, e Higinio Anglés (ed.): Tomás Luis de Victoria. Opera omnia. Vol. 4: Motetes XXII-XLVI, Barcelona, Consejo Superior de Investigaciones Científicas, 1968 (Monumentos de la Música Española XXXI), pp. 11-21. También S. Rubio: "Historia de las reediciones...", pp. 120-123 afirmó que la edición contenía variantes significativas respecto a los Motecta de 1583. Como bien apunta M. Ham: "Victoria as Self-Editor...", p. 282, no obstante, tales novedades se hallan ya en la publicación de 1583.

32 Para la historia editorial de todas las obras de Victoria, E. Cramer: Tomás Luis..., pp. 31-45.

33 S. Rubio: "Historia de las reediciones...", pp. 108-126 ; M. Ham: "Victoria as Self-Editor...", pp. $278-279$ 
la colección de valor en términos de autoridad textual ${ }^{34}$. Por contra, incrementa su interés desde el punto de vista de la recepción, pues nos obliga a buscar la motivación del proyecto en razones distintas a la iniciativa del compositor. Al menos dos especialistas, Iain Fenlon y Robert Stevenson, han propuesto planteamientos que responden a este imperativo. En una contribución reciente, Fenlon subraya el interés de tomar en consideración la influencia de Otto Truchsess von Waldburg ${ }^{35}$. El origen de la imprenta Mayer se remonta a 1550, cuando Von Waldburg instó al impresor Sebald Mayer, padre de Johann, a afincar su negocio en Dillingen. Adalid de la resistencia al avance del protestantismo e impulsor decisivo de la reforma tridentina,Von Waldburg se esforzó por convertir la ciudad, lugar de residencia del obispo de Augsburgo desde el siglo XV, en un baluarte del catolicismo. Entre 1549 y 1551 fundó allí una universidad. Dirigida inicialmente por la orden de los predicadores, pasaría a manos de la Compañía de Jesús en 1563, quedando así vinculada a la orden contrarreformista por antonomasia. El establecimiento de una imprenta se inscribe en el mismo proyecto. Von Waldburg buscaba dotar a la universidad, a su diócesis y, en suma, al catolicismo postridentino de un centro de publicación y distribución de literatura y propagand ${ }^{36}$. El perfil de producción de la imprenta Mayer es un claro reflejo de las circunstancias de la fundación. Junto a numerosos libros de teología y ascetismo, de sus prensas salieron gran cantidad de folletos propagandísticos; una parte más específica de su actividad, la publicación de manuales destinados a abastecer la labor educativa de los jesuitas y de documentos administrativos, evidencia el vínculo directo con la universidad y la autoridad diocesana ${ }^{37}$. Aunque la casa no estaba especializada en la impresión de música, entre las publicaciones figuran también numerosos libros de monodia sacra en latín y alemán, y dos colecciones de polifonía: las Cantiones sacrae de Victoria y, también de 1589, los Christliche Gesänge, Teutsche Psalmen de Jacob Reiner (1555/60-1606) ${ }^{38}$.

\footnotetext{
${ }^{34}$ Robert Stevenson: Spanish Cathedral Music in the Golden Age, Berkeley-Los Ángeles, University of California Press, 1961, p. 444; I. Fenlon: "From Print to Public...", p. 29; M. Ham: "Victoria as SelfEditor...", p. 282.

35 I. Fenlon: "From Print to Public...", p. 36.

36 Sobre la imprenta Mayer véase O. Bucher: "Sebald Mayer...", pp. 107-129 y O. Bucher: "Der Dillinger Buchdrucker Johann Mayer (1576-1614)", Gutenberg-Jahrbuch, 1955, pp. 162-169.

${ }^{37}$ Una lista de las publicaciones de la imprenta Mayer en Otto Bucher: Bibliographie der Deutschen Drucke des XVI. Jahrhunderts. Teil 1: Dillingen, Viena et al., Bad Bocklet, 1960 y O. Bucher: "Bibliographie der Druckwerke Johann Mayers und Seiner Witwe Barbara zu Dillingen 1601-1619”, Börsenblatt, 25, 1969, pp. 1573-1598. El volumen de publicaciones pone de manifiesto la relevancia adquirida por la imprenta: desde la fundación en 1550 hasta el fallecimiento de Johann Mayer, en 1615, se publicaron más de mil títulos.

${ }^{38}$ Josef Focht: "Die Musik im Umkreis der Jesuiten-Universität", Universität Dillingen und ihre Nachfolger. Stationen und Aspekte einer Hochschule in Schwaben, Rolf Kiessling (ed.), Dillingen an der Donau, Historischer Verein Dillingen, 1999, p. 549.
} 
La aportación de Fenlon trata un aspecto del mayor interés, como es la eventual influencia de determinadas personalidades de la escena eclesiástica germánica en el proceso de recepción de la música deVictoria. Asimismo, da cuenta de aspectos relevantes del contexto religioso-cultural en el que aparecieron las Cantiones sacrae. La importancia del trasfondo contrarreformista, en especial, resulta muy convincente. Sin embargo, es preciso subrayar que Von Waldburg falleció en 1573, de modo que su influencia dificilmente puede dar cuenta de las circunstancias inmediatas que motivaron una publicación aparecida diecisiete años más tarde. Acaso un pequeño matiz podría salvar este inconveniente: sustituir a Von Waldburg por la Compañía de Jesús como centro del argumento. El activo papel de la orden jesuita como agente difusor de todo tipo de bienes culturales a lo largo de la Edad Moderna es de sobra conocido $^{39}$. El fenómeno fue posible gracias a la excelente red de comunicaciones desarrollada por la Compañía entre sus numerosos colegios y, más importante para nuestro caso, entre estos y los colegios principales en Roma, que en muchos aspectos ejercían la función de modelo ${ }^{40}$.A tenor de la larga vinculación deVictoria con el Colegium Germanicum, cabe preguntarnos si la orden jugó algún papel en la recepción de su música en territorio germánico y, en particular, en la motivación de la publicación de Dillingen. Los jesuitas no solo dirigían allí la universidad sino que, desde 1568, y debido a problemas financieros por parte de Sebald Mayer, eran propietarios de la imprenta, sobre cuya producción ejercían un control estricto ${ }^{41}$. La hipótesis concuerda con el planteamiento de Fenlon al otorgar al contexto contrarreformista una relevancia esencial entre los factores que motivaron la publicación, al tiempo que solventa el problema cronológico que implica suponer una influencia activa por parte de Von Waldburg. Pero por el momento deberá quedar en el plano especulativo. Lo único que podemos afirmar con certeza es que los jesuitas de Dillingen se interesaron por el impreso deVictoria cuando ya había sido publicado. Así parece indicarlo el que se quedaran con un ejemplar, que figura en un inventario de la biblioteca de la Universidad realizado en $1594^{42}$.

\footnotetext{
${ }^{39}$ La bibliografía sobre el particular es muy extensa. Dos interesantes estudios que tratan aspectos distintos del fenómeno son Steven J. Harris: "Mapping Jesuit Science: The Role of Travelling in the Geopraphy of Knowledge", The Jesuits: Cultures, Sciences, and the Arts, 1540-1773, John W. O'Malley et al. (eds.), Toronto, University of Toronto Press, 1999, vol. 1, pp. 212-240 y Peter Burke: "The Jesuits and the Art of Translation in Early Modern Europe", John W. O'Malley et al. (eds.), The Jesuits: Cultures, Sciences, and the Arts, 1540-1773, Toronto, University of Toronto Press, 2006, vol. 2, pp. 24-32.

${ }_{40}$ Markus Friedrich: "Circulating and Compiling the Litterae Annuae. Towards a History of the Jesuit System of Communication", Archivum Historicum Societatis Iesu, 77, 2008, pp. 3-39.

${ }^{41}$ Los problemas financieros que afectaron a Sebald Mayer desde la fundación de la imprenta se hicieron insostenibles en la década de 1560, de modo que, con el fin de evitar la bancarrota, Otto von Waldburg se vio obligado a comprar la empresa, que a continuación donó a los jesuitas. O. Bucher: "Der Dillinger Buchdrucker...", pp. 162-163.

42 Josef Focht: "Die Musik im Umkreis...", p. 554.
} 
Robert Stevenson propuso un planteamiento totalmente distinto al de Fenlon, y sugirió que la aparición de las Cantiones sacrae se pudiera explicar por la propia notoriedad de los motetes de Victoria en el momento de la publicación ${ }^{43}$. En otras palabras, interpretó el impreso de Dillingen como la manifestación más evidente de un fenómeno de circulación que se remontaría a una fecha anterior a 1589. Tanto como en la aparente desvinculación de Victoria, esta hipótesis se fundamenta en la suposición de que el impreso de Dillingen respondió a una iniciativa de carácter profesional y que, como tal, estuvo motivada por fines comerciales. La financiación de un impreso musical por parte de un profesional del ámbito del libro, ya sea un impresor, editor, librero, etc., implica un escenario en el que el factor económico adquiere una importancia primordial. El riesgo que supone costear una publicación conlleva ciertas estrategias de planificación, entre las que contar con expectativas de venta es sin duda una de las principales. Y no hay mejor garantía para considerar un cierto mercado que la popularidad del repertorio a publicar.

Este segundo planteamiento es interesante porque proporciona un marco posible en el que circunscribir el pasaje que abre nuestra contribución. Las palabras de Mayer sugieren que, a finales de la década de 1580, Victoria gozaba de cierto prestigio en territorio germánico; un prestigio que, es lógico suponer, se derivaría de una valoración positiva de sus obras, lo que a su vez sugiere un fenómeno de circulación previo. Por otro lado, es evidente que, en la medida en que no aparezcan datos que refuten la desvinculación de Victoria, habrá que aceptar la posibilidad de que tras la publicación de sus motetes se hallara alguien distinto al compositor. De hecho, contamos con indicios de la responsabilidad del propio impresor al respecto. Que de él surgió la iniciativa se desprende claramente del siguiente pasaje de la dedicatoria a Von Gemmingen: “[...] pensé que estas canciones [...], muy apropiadas para deleitar los oídos con dulzura sinfónica y para provocar el sentimiento de piedad en las almas de los hombres, debía yo publicarlas y dedicarlas al nombre de tu Excelencia" ${ }^{44}$. El que Mayer se valiera de la función característica de la dedicatoria -conseguir el favor de la personalidad a la que va dirigida- parece además indicar que asumió los costes de la tirada y, con ello, el eventual riesgo comercial de la empresa ${ }^{45}$.

\footnotetext{
${ }^{43}$ R. Stevenson: Spanish Cathedral..., p. 448. El musicólogo no desarrolla el argumento, limitándose a afirmar que la publicación del impreso denota que "Victoria's motets were sufficiently popular in Germany". Véase también A. Sabe: Tomás Luis..., p. 156.

44 "Has inquam Cantiones, et ad aures Symphonica suavitate mulcendas et pietatis etiam sensum in hominum animis excitandum accomodatissimas [...], mihi excudendas tuaque Ampludini noncupandas putavi". Tomás Luis de Victoria: Cantiones sacrae (Dillingen, 1589), carta dedicatoria escrita por el impresor Johann Mayer. Luis González Platón: "Traducción...”, p. 223.

45 Un caso parecido es el de los Hymni de 1600, precedidos por una dedicatoria escrita por el editor.
} 
Por interesante que resulte, carecemos de testimonios documentales que respalden el argumento de Stevenson. Al no contar con el contrato de impresión, ignoramos los detalles que permitirían una reconstrucción veraz del perfil del proyecto y una valoración fidedigna de sus implicaciones en términos comerciales y, por consiguiente, de notoriedad. A la espera de nueva documentación, en cualquier caso, el estado de la cuestión justifica el ejercicio de determinar si -requisito principal del argumento de Stevenson- existen indicios de una circulación en la zona de la música de Victoria anterior a 1589, tema sobre el que volveremos más adelante. Sirva por el momento lo hasta aquí expuesto para poner de manifiesto el interés de la publicación de Dillingen como referencia historiográfica. Como hemos tratado de argumentar, el evento permite estructurar el acercamiento del investigador en dos direcciones alternativas. Es probable que las Cantiones sacrae representaran un impulso fundamental para la difusión de la obra de Victoria en territorio germánico a partir de 1589, hipótesis a la que corresponden trabajos de investigación que documenten el impacto de la colección ${ }^{46}$. Pero también cabe interpretar su aparición como parte de un contexto más amplio, cuyo origen se podría remontar unos años atrás. En efecto, las circunstancias de la empresa reclaman estudios que se interesen por determinar los factores que motivaron la publicación, entre ellos la eventual recepción previa de los motetes deVictoria en el territorio. Este último enfoque representa el principio motriz de la presente contribución.

Si la publicación de las Cantiones sacrae marca la incorporación de los motetes de Victoria al mercado alemán de música impresa, la siguiente fuente documenta otra faceta del mismo fenómeno de circulación: la inclusión del repertorio en el canon musical de instituciones eclesiásticas. La fuente en cuestión es un ceremonial redactado entre 1585-1592 para las iglesias evangelistas de Hof, localidad situada al norte de la actual Baviera que abrazó las doctrinas luteranas desde fecha muy temprana. Su título completo reza Ordo eorum, quae in omnibus sacris actibus, ad S. Michaelis, quae Curiae parochialis ecclesia est, diebus tam festis quam profestis, ad laudem Dei opt[imi] max[imi] et ad animos piorum in vero Dei cultu exuscitandos et retinendos religiose observantur ${ }^{47}$. En la época en que se redactó el documento, la música litúrgica de Hof era responsabilidad de una capilla musical financiada por

\footnotetext{
${ }^{46}$ Esta cuestión es el objeto de un artículo actualmente en preparación. Contribuciones anteriores que aportan datos en la misma dirección pueden consultarse en Samuel Rubio: "¿Son de Victoria la 'Missa dominicalis' y el himno 'Jesu dulcis memoria'?", Samuel Rubio (1912-2012). In memoriam. Estudios sobre Tomás Luis de Victoria, José Sierra Pérez (ed.), 2012, pp. 38-40, y David Crook: "A Sixteenth-Century Catalog of Prohibited Music", Journal of the American Musicological Society, 62/1, 2009, pp. 18 y 59.

${ }^{47}$ Hof Dekanat, Dekanatsregistratur XLIX 24. El ceremonial completo está publicado en Emil Sehling (ed.): Die evangelische Kirchenordnungen des XVI Jahrhundert, Band XI/1: Bayern: Franken, Tübingen, J.C.B. Mohr, 1961, pp. 405-477. Para la parte relativa a la música, véase Heinrich Kätzel:
} 
la municipalidad. Participaba en celebraciones de distintos centros de la ciudad, aunque estaba especialmente vinculada a la institución eclesiástica principal, la iglesia parroquial de San Miguel. A ello se debe que el ceremonial, en realidad destinado a prescribir la liturgia de todas las iglesias evangelistas del lugar, incluya en su título una referencia explícita a este centro. La dirección de la capilla estaba asociada a los cargos de magister del Gymnasium Albertinum, institución de cuyo alumnado procedían la mayor parte de los cantores que la conformaban. La estrecha vinculación entre el Albertinum y San Miguel, aspecto fundamental de la realidad litúrgico-musical de Hof, constituye un elemento clave para comprender la génesis de nuestra fuente ${ }^{48}$.

Antecedente directo del Ordo, el primer ceremonial destinado a regular la actividad litúrgica de los centros de Hof que se convirtieron a la nueva confesión fue redactado en 1529. El proyecto lo realizaron Kaspar Löner y Nikolaus Medler, teólogos reformistas que jugaron un papel destacado en la formación de la liturgia de la nueva Hof protestante ${ }^{49}$. Por entonces predicador de San Miguel, Löner se encargó de redactar la sección relativa a la organización del culto. Medler, rector de la escuela latina (Lateinschule) que pocos años después sería refundada en el Gymnasium Albertinum, confeccionó la parte musical. Los dos documentos resultantes de esta labor fueron depositados en San Miguel, donde se conservaron durante décadas hasta que, entre 1570 y 1580 , se extravió la parte confeccionada por Medler, lo que entrañó un rápido deterioro de la actividad musical de la institución. Al menos esta es la versión de los hechos tal como la expone Enoch Widmann (15511617), nombrado maestro de música del Albertinum en 1581 y responsable de la redacción de un nuevo ceremonial, el Ordo, unos años más tarde ${ }^{50}$.

Durante el tiempo que estuvo vinculado al Albertinum, Enoch Widmann, que ocupó diversos cargos hasta ser nombrado rector en 1596, desempeñó una importante labor como autor y copista. Además del nuevo ceremonial, de su pluma salieron numerosos manuscritos de música y una crónica de la ciudad por la que es mayormente conocido ${ }^{51}$. La confección del Ordo se prolongó por un espacio de siete años: Widmann comenzó la labor en 1585 y entregó el documento en 1592. Con un extensión de 137

Musikpflege und Musikerziehung im Reformationsjahrhundert dargestellt am Beispiel der Stadt Hof, Göttingen, Vandenhoeck \& Ruprecht, 1957. Deseo agradecer a Christian Leitmeier el haberme facilitado la referencia de esta fuente.

48 Sobre la actividad, los integrantes y la dirección de la capilla, véase H. Kätzel: Musikpflege und Musikerziehung..., pp. 89-98.

${ }^{49}$ Ambos fueron alumnos de Martin Lutero en la Universidad de Wittenberg. Ludwig Stühlmeyer: Curia sonans: Die Musikgeschichte der Stadt Hof. Eine Studie zur Kultur Oberfrankens von der Gründung des Bistums Bamberg bis zur Gegenwart, Bamberg, Heinricus, 2010: Curia sonans..., p. 91.

${ }^{50}$ H. Kätzel: Musikpflege und Musikerziehung..., pp. 27-28.

${ }^{51}$ La crónica nos ha llegado en numerosas copias manuscritas, hoy conservadas en diferentes archivos alemanes. H. Kätzel: Musikpflege und Musikerziehung..., pp. 15-16. 
folios, está organizado en veintidós capítulos que describen de forma detallada la estructura y contenido de la actividad cultual de San Miguel y demás centros de la ciudad ${ }^{52}$. Varias de sus secciones, las que interesan a nuestro propósito, incluyen referencias a polifonía. La principal, titulada Ordo suavissimarum... figurali musica, especifica las piezas a interpretar durante la misa y oficios principales de todas las celebraciones del calendario litúrgico ${ }^{53}$. Pero también registran música polifónica otros capítulos dedicados a ceremonias que, como en el caso de las nupcias, no pertenecen al calendario ${ }^{54}$. Lo prolijo de la información relativa a la música confiere a este documento un valor excepcional, pues además de especificar la posición litúrgica exacta de cada una de las piezas, incluye información -íncipit textual, nombre del compositor y número de voces- que facilita en extremo su identificación.

Aunque incluye referencia a algunas piezas en lengua germánica, la mayor parte del repertorio polifónico que aparece en el Ordo de Hof es en latín. El dato refleja el conocido fenómeno de que a lo largo de todo el siglo XVI las capillas de los centros protestantes continuaron interpretando regularmente, aunque con salvedades, polifonía de tradición católica ${ }^{55}$. Conforman el repertorio todo tipo de géneros, con predominio del motete, cuya interpretación es prescrita para distintas partes de la misa y como opción alternativa a algunas secciones de las Vísperas. Aunque prevalecen compositores de origen germánico, el documento recoge un volumen importante de repertorio internacional, reflejando un canon musical que se habría ido conformando a lo largo de todo un siglo: recoge obras de autores de diversas generaciones, desde compositores nacidos en la segunda mitad del siglo XV, como Josquin, Obrecht e Isaac, hasta aquellos que se encontraban en plena madurez compositiva en la época de la redacción del documento.

Entre los compositores más modernos representados en el Ordo, dos ocupan un lugar principal. Citado unas setenta veces, el compositor mejor representado es Orlando de Lasso, dato poco sorprendente dada la extraordinaria circulación de que gozaba la música de este compositor en todo el territorio de habla germánica. Más notable es advertir que el siguiente autor mejor representado es Tomás Luis de Victoria, cuya música es prescrita en más de treinta ocasiones. A considerable distancia en términos de presencia destacan compositores de generaciones anteriores, como

2 E. Sehling (ed.): Die evangelische..., p. 405.

53 Ibid., pp. 456-471. El título completo del capítulo reza Ordo suavissimarum et optimarum ex praestantissimis artificibus, tum veteribus tum recentibus, selectarum cantionum, quae in ecclesia curiensi ad D. Michaelem, in musica figurali, cantore duce, decantantur, ad praecipua festa totius anni directus.

${ }^{54} \mathrm{La}$ sección de las nupcias se puede consultar en E. Sehling (ed.): Die evangelische..., p. 430.

55 Sobre esta cuestión véase Mary E. Frandsen: "Salve Regina - Salve Rex Christe: Lutheran Engagement with the Marian Antiphons in the Age of Orthodoxy and Piety", Musica Disciplina, 55, 2010, pp. 129-218. 
Clemens non Papa, mencionado doce veces, y Josquin y Senfl, con once apariciones cada uno. El Cuadro 1 lista las piezas de Victoria recogidas en el ceremonial, el contexto litúrgico donde aparecen y los impresos en que se publicaron hasta la fecha en que Widmann entregó el documento. El Ordo incluye veinticinco motetes atribuidos al abulense, algunos prescritos para más de una festividad -de ahí que el número de apariciones sea superior a la cantidad de piezas musicales-. El que especifique los contextos de interpretación, y no simplemente las festividades, representa sin duda uno de los atractivos de la fuente. Si contar con testimonios coetáneos que nos provean de este tipo de información es poco habitual, en el marco de la historiografia dedicada a Victoria el Ordo adquiere un valor excepcional. Igualmente destacable es que tres de las piezas que recoge, Ecce Maria genuit, Ecce Virgo concipiet y Velum templi, no se publicaran en ninguno de los impresos del compositor -el resto fue publicado en repetidas ocasiones- ni figuren, hasta donde sabemos, en fuente manuscrita alguna que sugiera que efectivamente salieron de su pluma ${ }^{56}$. Suponiendo que se trate de atribuciones correctas, vendrían a engrosar la lista de obras de Victoria sobre las que solo contamos con referencias documentales ${ }^{57}$.

El ceremonial de Hof documenta un caso de extensa incorporación de Victoria al canon musical de una institución del contexto germánico. La presencia del abulense se torna especialmente destacada al cotejarla con la de otros autores coetáneos. Es de resaltar, por ejemplo, que compositores de la generación de Victoria activos en el territorio aparezcan mucho menos representados, caso de Jacob Meiland (1542-1577) y Joachim a Burck (15461610), de quienes el Ordo recoge diez y cinco piezas, respectivamente ${ }^{58}$. La comparación con Meiland es especialmente interesante por cuanto se trata de un compositor cuya música gozó de una importante circulación en la zona ${ }^{59}$. Cabe mencionar también la diferencia respecto a Palestrina, cuya música gozó de cierta recepción, al menos en la región de Baviera, y que solo aparece mencionado en dos ocasiones a lo largo de todo el ceremonial ${ }^{60}$. Como Victoria, se trata de un compositor extranjero, también activo en Roma, por lo que la categoría en calidad de la cual ambos autores serían objeto de recepción al norte de los Alpes pudiera parecer equiparable.

\footnotetext{
${ }^{56}$ E. Cramer: Tomás Luis..., pp. 89-107.

${ }^{57}$ Ibid., pp. 107.

58 Sobre la actividad documentada de estos compositores, véase Christian Bettels: "Meiland, Jakob", $M G G^{2}$, Personenteil, vol. 11, cols. 1482-1483 y Joachim Stalmann: "Burck, Joachim a", MGG2, Personenteil, vol. 3, cols. 1278-1279.

59 Walter Blankenburg: "Meiland, Jacob", $N G^{2}$, vol. 16, p. 291.

60 Sobre la recepción de Palestrina en Baviera durante el siglo XVI, véase Siegfried Gmeinwieser: "Palestrina und Palestrinastil in Bayern", La recezione di Palestrina in Europa fino all Ottocento, Rodobaldo Tibaldi (ed.), Lucca, Libreria Musicale Italiana, 1999, pp. 195-207.
} 
Cuadro 1. Motetes de Victoria en el ceremonial de Hof (1592)

\begin{tabular}{|c|c|c|c|c|c|}
\hline & Motete & Voces & Festividad & Contexto & Publicaciones (hasta 1592$)^{6}$ \\
\hline 1. & Ascendens Christus & 5 & Ascensión & Post Evangelium & $1572,1583 b, 1585 b, 1589$ \\
\hline 2. & Benedicta sit & 6 & $\begin{array}{l}\text { Trinidad } \\
\text { Último domingo de Trinidad }\end{array}$ & $\begin{array}{l}\text { Post Evangelium } \\
\text { Loco "Nun bitten wir" }\end{array}$ & 1572, 1583b, 1585b, 1589 \\
\hline 3. & Cong ratulamini mihi & 6 & Circuncisión & Loco "Nun bitten wir" & $1572,1583 \mathrm{~b}, 1585 \mathrm{~b}, 1589$ \\
\hline 4. & Cum beatus Ignatius & 5 & Conversión de San Pablo & Post Evangelium & $1572,1583 b, 1589$ \\
\hline 5. & Descendit angelus & 5 & San Juan Bautista & Loco "Nun bitten wir" & 1572, 1583b, 1585b, 1589 \\
\hline 6. & Doctor bonus & 4 & San Andrés Apóstol & Post Evangelium & 1572, 1583b, 1585b, 1589 \\
\hline 7. & Dum complerentur & 5 & $\begin{array}{l}\text { Pentecostés } \\
\text { Conmemoración del Albertinum }\end{array}$ & $\begin{array}{l}\text { Ante Concionem } \\
\text { Sub Communione }\end{array}$ & $1572,1583 b, 1585 b, 1589$ \\
\hline 8. & Ecce Dominus veniet & 5 & Primer domingo de Adviento & Post Evangelium & $1572,1583 b, 1585 b, 1589$ \\
\hline 9. & Ecce Maria genuit & 8 & Circuncisión & Post Epistolam & - \\
\hline 10. & Ecce virgo concipiet & 5 & Anunciación & Post Epistolam & - \\
\hline 11. & Magi viderunt stellam & 4 & Epifanía & Sub Communione & 1572, 1583b, 1585b, 1589 \\
\hline 12. & $\mathrm{O}$ magnum mysterium & 4 & Circuncisión & Sub Communione & $1572,1583 b, 1589$ \\
\hline 13. & O quam gloriosum & {$[4]$} & San Simón y San Judas & Loco "Nun bitten wir" & $1572,1583 b, 1585 b, 1589$ \\
\hline 14. & O sacrum convivium & 4 & $\begin{array}{l}\text { Dedicación Iglesia San Miguel } \\
\text { Conversión de San Pablo }\end{array}$ & $\begin{array}{l}\text { Sub Communione } \\
\text { Sub Communione }\end{array}$ & 1572, 1583b, 1585b, 1589 \\
\hline 15. & O sacrum convivium & 6 & $\begin{array}{l}\text { San Juan Bautista } \\
\text { San Lorenzo } \\
\text { Domingo de Quasimodo }\end{array}$ & $\begin{array}{l}\text { Sub Communione } \\
\text { Sub Communione } \\
\text { Sub Communione }\end{array}$ & $\begin{array}{l}1572,1576,1583 b, 1585 b \\
1589\end{array}$ \\
\hline 16. & O vos omnes & 4 & Domingo de Ramos & Loco "Nun bitten wir" & $1572,1583 \mathrm{~b}, 1589$ \\
\hline 17. & Pueri hebraeorum & 4 & Domingo de Ramos & Loco "Nun bitten wir" & $1572,1583 \mathrm{~b}, 1585 \mathrm{a}, 1589$ \\
\hline 18. & Quam pulchri sunt & 4 & Nupcias & & $1572,1583 b, 1585 b, 1589$ \\
\hline 19. & Quem vidistis pastores & 6 & Navidad & Post Epistolam & $1572,1583 b, 1585 b, 1589$ \\
\hline 20. & Surrexit pastor bonus & 6 & Lunes de Pascua & Post Epistolam & $1572,1583 b, 1585 b, 1589$ \\
\hline 21. & Tu es Petrus & 6 & San Pedro y San Pablo & Post Evangelium & $1572,1583 b, 1585 b, 1589$ \\
\hline 22. & Vadam et circuibo & 4 & Nupcias & & 1572, 1583b, 1585b, 1589 \\
\hline 23. & Velum templi & 5 & Domingo de Ramos & Loco "Nun bitten wir" & - \\
\hline 24. & Vere languores & 4 & Domingo de Ramos & Loco "Nun bitten wir" & $1572,1583 b, 1585 a, 1589$ \\
\hline 25. & Vidi speciosam & 6 & $\begin{array}{l}\text { Visitación } \\
\text { Nupcias }\end{array}$ & Loco "Nun bitten wir" & $\begin{array}{l}1572,1576,1583 b, 1585 b \\
1589\end{array}$ \\
\hline
\end{tabular}

El Ordo resulta el lógico complemento histórico de la publicación de Dillingen. A la aparición en el territorio de una reedición de los motetes deVictoria parecerían corresponder ejemplos de incorporación notable de la música del compositor. Sin embargo, por el momento ningún indicio permite pensar que nos hallemos ante un ejemplo representativo. Ello no merma el extraordinario interés del caso, y es que faltan documentos coetáneos comparables, no ya en el contexto germánico, sino en entornos que, como el italiano y el hispánico, han sido objeto de extensa atención por parte de los especialistas. La conservación de numerosos impresos de

${ }^{61}$ Motecta (Venecia, 1572) [=1572], Missarum liber primus (Roma, 1576) [=1576], Motecta (Roma, 1583) [=1583b], Officium Hebdomadae Sanctae [1585a], Motecta festorum totius anni [=1585b], Cantiones sacrae (Dillingen, 1589) [=1589]. 
Victoria en archivos italianos indica de forma clara la presencia de los motetes del compositor en el panorama musical del territorio, pero faltan estudios que se ocupen de los ejemplares de forma individualizada y que dibujen una imagen clara de su uso efectivo ${ }^{62}$. Desde luego, no se conoce documento alguno que, como el Ordo, confirme de manera explícita un grado tan notable de incorporación de este repertorio al canon musical de una institución concreta, o que provea información sobre su contexto litúrgico específico. Tampoco del contexto hispánico se conoce un documento parecido, aunque, en este caso, una mayor dedicación a los ejemplares conservados de sus impresos ha permitido determinar de forma efectiva la adopción de los motetes deVictoria en el repertorio musical de centros concretos ${ }^{63}$.

La pregunta obvia que suscita el Ordo evidencia la concomitancia respecto al caso de las Cantiones sacrae: ¿cómo explicar tan amplia representación de un compositor activo en el extranjero en el canon musical de Hof? Lamentablemente, la concomitancia afecta también a la dificultad de hallar una respuesta. Es probable que la incorporación de los motetes del abulense se viera favorecida por la elección personal de los responsables de la actividad musical de la ciudad, los maestros del Gymnasium Albertinum, y, más concretamente, por el redactor del ceremonial. En la época en que comenzó la confección del documento, Enoch Widmann ocupaba el tercer cargo en importancia (colega tertius) de la institución, siendo nombrado corrector (1591) durante el proceso de redacción ${ }^{64}$. Sin duda, su autoridad jugaría un papel relevante en el proceso de incorporación de nuevo repertorio. Al mismo tiempo, parece dificil aceptar que, quienquiera que tomara la decisión de interpretar motetes de Victoria en Hof, se decidiera a incorporar veinticinco piezas de un compositor totalmente desconocido. De nuevo, constatamos el interés de mejorar nuestro conocimiento sobre la posición de Victoria en el panorama musical germánico durante la década de 1580.

Cuestiones distintas al porqué de la adopción, aunque estrechamente vinculadas, son la fecha de recepción de los motetes de Victoria en Hof y su filiación. En especial, sería útil determinar si nos hallamos ante un reflejo del impacto de las Cantiones sacrae o bien ante un testimonio de un fenómeno de circulación previo. A pesar de que carecemos de información sobre la realidad musical de Hof antes de la confección del Ordo, contamos con un segundo documento que permite arrojar algo de luz sobre el

\footnotetext{
62 Un panorama completo de las fuentes conservadas en Italia lo presentó Noel O'Regan: "Italian Sources for the Music of Tomás Luis de Victoria", ponencia leída en el Workshop Musicology and Informatics in Dialogue: Problems of Transmission and Possibilities of Analysis in the Oeuvre of Tomás Luis de Victoria (ca. 1548-1611) celebrado en la Universität des Saarlandes (Saarbrücken), septiembre de 2015.

${ }^{63} \mathrm{~J}$. Ruiz: "Recepción y pervivencia...", p. 324.

${ }^{64}$ H. Kätzel: Musikpflege und Musikerziehung..., p. 100.
} 
particular. Al final del manuscrito que copia el ceremonial, y tras unos cuantos cuadernos en blanco, se halla un inventario de los libros de música de San Miguel ${ }^{65}$. Iniciado por Widmann, fue completado por sucesivos copistas a lo largo de todo el siglo XVII. Aunque un estudio completo de este documento queda fuera del marco de nuestra contribución, atender brevemente a su contenido habrá de proveernos de información valiosa.

La parte del inventario copiada por Widmann lista un total de cuarenta y un ítems, recogiendo libros manuscritos e impresos, tanto de canto llano como de polifonía. Ninguna fecha encabeza el documento, por lo que es difícil determinar cuándo se inició el registro. Pero es indiscutible que la labor se prolongó más allá de 1592. Algunas entradas incluyen indicación del año de copia de la fuente, de su incorporación al fondo de San Miguel, o bien registran impresos que podemos identificar, y gracias a estas entradas es posible reconstruir parcialmente la cronología de redacción. El vigésimo tercer ítem, por ejemplo, es un gradual copiado entre 1593 y 1595 que demuestra que al menos la mitad de los libros registrados por Widmann fueron incluidos cuando el Ordo ya había sido entregado.

El inventario incluye dos referencias a libros con música deVictoria. Registrada antes del mencionado gradual, la primera es un conjunto de "seis partes con piezas de Luis de Victoria, copiados por mí, en folio" "66. Aunque la entrada no incluye especificación alguna sobre el contenido, con toda probabilidad esta fuente recogería los motetes de Victoria que aparecen en el Ordo. La segunda referencia forma parte de un grupo de libros que llegó a San Miguel cuando la redacción del ceremonial ya había finalizado. A juzgar por la anotación que lo precede, el grupo fue donado por el propio Widmann en 1596. La última entrada de este grupo, un conjunto de "ocho libretes en cuarto", incluye tres colecciones, sin duda tres impresos encuadernados juntos. Solo del primero, la antología Corollarium sacrarum cantionum publicada por Friedrich Lindner (Núremberg, 1590), se nos facilita información suficiente para su identificación. Para los dos siguientes, Widmann se limitó a la escueta anotación "Ítem del Sr. Ludovico a Victoria y algunos salmos a cuatro voces" $"$. A juzgar por el formato, la colección de Victoria solo pudo responder a tres de los impresos del abulense publicados hasta la fecha: los Motecta de 1583 o alguna de sus reediciones de 1589.

Ante la ausencia de la música, no hay modo de determinar de forma concluyente el contenido de la colección de libretes manuscritos que figura

\footnotetext{
${ }^{65}$ Reproducido en H. Kätzel: Musikpflege und Musikerziehung..., pp. 47-49.

66 "Sechs partes, darinnen des Ludovici a Victoria gesenge, von mir geschrieben, in folio", H. Kätzel: Musikpflege und Musikerziehung..., p. 48.

67 "Item des Herrn Ludovico a Victoria, und ettliche psalmi 4 vocum", H. Kätzel: Musikpflege und Musikerziehung..., p. 49.
} 
en el inventario, de saber si fue copiado de alguno de los impresos de Victoria, y en tal caso de cuál. Los datos hasta aquí expuestos no permiten ni siquiera acotar el marco cronológico. De hecho, el modelo pudo ser el propio impreso donado porWidmann en 1596 -que pasara entonces a engrosar la biblioteca de San Miguel no implica que Widmann no pudiera haberlo adquirido años antes-, y por lo tanto hallarse en las Cantiones sacrae ${ }^{68}$. Sin embargo, suponer una filiación estrictamente impresa impide justificar la atribución al abulense de los tres motetes que no aparecen en ninguna de sus publicaciones. Contamos además con indicios de que conviene situar el modelo original de los libretes en un proceso de transmisión anterior a la publicación de Dillingen, a saber, los datos cronológicos que se derivan del cotejo detallado entre los libros del inventario y la música recogida en el ceremonial.

Aunque incluye manuscritos cuyo contenido no se especifica, y que probablemente copiaban algunas de las piezas prescritas en el Ordo, el inventario recoge varias antologías impresas que permiten identificar el origen de la mayor parte de las piezas prescritas para la liturgia de Hof. Tales antologías se hallan en la primera parte del inventario, es decir, fueron registradas antes del gradual de 1593-95. De la comparación entre el inventario y el contenido del ceremonial se colige un dato interesante: el impreso más tardío común a ambos documentos son las Cantiones sacrae de Friedrich Lindner, publicadas en Núremberg en $1585^{69}$. El ceremonial no incluye una sola pieza de impresos posteriores que, en cambio, también aparecen recogidos en el inventario. Es el caso de otra antología de Lindner, la Continuatio cantionum sacrarum (Núremberg, 1588), un impreso que recoge composiciones de autores que en años venideros gozarían de una destacada recepción en territorio germánico, tales como Andrea y Giovanni Gabrieli o Hans Leo Hassler, y de un volumen de la serie Opus musicum de Jacob Handl (Praga, 1586-1590) -aunque Widmann no especificó de qué volumen se trata, el ceremonial no prescribe composiciones de ninguno de ellos-. Parece, así, que el Ordo refleja el repertorio musical interpretado en Hof a mediados de la década de 1580, en cuyo caso, las posibilidades para la filiación original se reducirían a dos de los impresos del abulense, los libros de motetes de 1572 y 1583 . Aunque no es un elemento concluyente, inclina la balanza a favor del primero el que, al margen de las tres piezas para

\footnotetext{
${ }^{68}$ Eso sí, el supuesto implicaría aceptar que las secciones del ceremonial que incluyen piezas del abulense fueron redactadas entre 1589 y 1592.

${ }^{69}$ El ceremonial recoge siete motetes de la antología de Lindner: Quem vidistis pastores de Jean Pennequin (actividad documentada entre 1577-1585), Maria Magdalena de Tiburzio Massaino (antes de 1550-1608), Puer natus est y Viri Galilei de Palestrina y O rex gentium, O altitudo divitiarum e In Deo speravi de Claudio Merulo (1533-1604). Estas piezas aparecen prescritas en los mismos contextos propuestos en el índice de la fuente impresa.
} 
las que no contamos con atribuciones a Victoria en fuente alguna, todas las obras del abulense recogidas en el ceremonial de Hof figuren ya en la colección de 1572. Es decir, que el Ordo no recoge ni una sola de las veinte piezas nuevas que presenta el impreso de 1583 respecto al anterior ${ }^{70}$.Ya sea fruto de la casualidad, o acaso el reflejo de un determinado criterio de selección, el dato respalda la conveniencia de situar la fuente original de la música de Victoria interpretada en Hof en un proceso de transmisión anterior a las Cantiones sacrae.

Al margen de especulaciones sobre la filiación del repertorio, el contenido del ceremonial de Hof apunta a la misma idea que se deriva de las Cantiones sacrae: el interés por documentar la recepción de la música de Victoria en el contexto germánico antes de 1589. En el supuesto de que el impulso de la publicación de Dillingen se hallara en una cierta notoriedad de los motetes que recoge, ¿dónde están los testimonios que la documentan? De igual modo, si el contenido del Ordo es deudor de una transmisión anterior a 1589, ¿qué pruebas fehacientes demuestran la recepción correspondiente? Responder a estas preguntas requiere del examen combinado de fuentes de tipo diverso, entre ellas documentación normativa e inventarios. Por nuestra parte, nos limitaremos a contribuir con uno de los pasos imprescindibles del ejercicio y atenderemos a las fuentes prácticas, impresas y manuscritas.

Hasta la aparición de las Cantiones sacrae, Victoria publicó cinco colecciones con motetes, tres dedicadas de forma monográfica al género y otras dos que, aunque destinadas fundamentalmente a otro tipo de piezas, incluyen unos cuantos ejemplos del mismo. El Cuadro 2 recoge todos los ejemplares de estas colecciones conservados en archivos alemanes. Como se aprecia claramente, el conjunto es realmente reducido, limitándose a un ejemplar de los Motecta de 1572, uno de los Cantica de 1581 y dos de los Motecta de 1583. De la recepción de las otras dos colecciones de Victoria que incluyeron motetes, el Liber primus de 1576 y los Motecta festorum totius anni de 1585, si existió, no contamos con prueba alguna. El escenario se ve drásticamente limitado por el hecho de que tres de las cuatro fuentes recogidas en el cuadro no llegaron a su paradero actual sino en fecha relativamente reciente. El ejemplar de los Motecta de 1572 conservado en la Diözesanbibliothek de Münster (Cuadro 2,1) forma parte de la colección de fuentes musicales reunida por el clérigo y compositor Fortunato Santini (1778-1861), que no alcanzó suelo alemán hasta después de la muerte de este, en $1862^{71}$.

\footnotetext{
${ }^{70}$ Aunque nuevas respecto al impreso de 1572, muchas de ellas ya habían aparecido en colecciones anteriores a 1583 .

${ }^{71}$ Joseph Killing: Kirchenmusikalische Schätze der Bibliothek des Abbate Fortunato Santini. Ein Beitrag zur Geschichte der katholischen Kirchenmusik in Italien, Düsseldorf, Schwann, 1910, pp. 20-21.
} 
El ejemplar de los Cantica (Cuadro 2,2) y una de las copias de los Motecta de 1583 (Cuadro 2, 3) deben su presencia en la Bischöfliche Zentralbibliothek de Regensburg a la labor recopilatoria de Franz Xaver Haberl (1840-1910). Sacerdote, músico, musicólogo y figura importante en el proceso de recuperación decimonónica de la polifonía vocal clásica, Haberl adquirió numerosas fuentes en Italia que, a su muerte, fueron incorporadas al fondo de dicha biblioteca. Entre ellas los dos libros deVictoria, parte integrante de un grupo de fuentes procedentes del Collegium Germanicum de Roma ${ }^{72}$, como confirma, en el caso de los Motecta, la anotación 'Coll[egium] Ger[mani]ci' a ambos lados de la estampa de la portada (Ilustración 2).

Cuadro 2. Ejemplares en archivos alemanes de impresos de Victoria anteriores a 1589 con motetes

\begin{tabular}{|c|c|c|}
\hline Impreso & N. ${ }^{\circ}$ de motetes & Ejemplares conservados \\
\hline Motecta (Venecia, 1572) & 33 & (1) Münster, Diözesanbibliothek, Santini Dr. 742 \\
\hline Liber primus qui missas... (Venecia, 1576) & 15 & - \\
\hline Cantica B. Virginis (Roma, 1581) & 8 & (2) Regensburg, Bischöf. Hofbib., B.H. 6012 \\
\hline Motecta (Roma, 1583) & 53 & $\begin{array}{l}\text { (3) Regensburg, Bischöf. Hofbib., B.H. } 6226 \\
\text { (4) Regensburg, Bischöf. Hofbib., A. R. } 470\end{array}$ \\
\hline Motecta festorum totius anni (Roma, 1585) & 37 & - \\
\hline
\end{tabular}

La segunda copia de los Motecta conservada en la Bischöfliche Zentralbibliothek (Cuadro 2,4) representa el único testimonio de la recepción en territorio germánico de un impreso de motetes de Victoria anterior a las Cantiones sacrae. La propia publicación de Dillingen, claro está, demuestra de forma indiscutible el acceso por parte de Johann Mayer al impreso que sirvió de modelo para la reedición. Sin embargo, en la medida en que la vía de acceso nos es desconocida, conviene no equiparar este dato con una circulación efectiva. El ejemplar de Regensburg es un caso distinto, pues dos anotaciones en la portada permiten identificar su localización a partir de 1597 (Ilustración 3). Situada en la parte superior de la página, la primera, que reza "Societatis Jesus Ratisponae 1597", revela que en dicho año pertenecía al colegio jesuita de San Pablo, en la misma ciudad. La Compañía de Jesús había llegado a Regensburg en 1589, ocupando un viejo monasterio hasta entonces habitado por monjas canónigas. El estado ruinoso del edificio requirió de una completa renovación, llevada a cabo con gran celeridad: en 1591 se consagró la nueva iglesia y en 1597 se inauguró oficialmente el colegio ${ }^{73}$.

72 Johannes Hoyer (ed.): Bibliothek Franz Xaver Haberl, vol. 1, Múnich, Henle, 1996 (Kataloge Bayerische Musiksammlungen, vol. 14/6), p. XIII. Sobre la figura de Haberl, véase Franz Karl Praßl: "Haberl, Franz Xaver", $M G G^{2}$, Personenteil, vol. 8, cols. 353-354.

73 Josef Klose: "Das Gymnasium und Lyzeum St. Paul zu Regensburg", Albertus-Magnus-Gymnasium Regensburg. Festschrift zum Schuljubiläum 1988. Regensburg, Albertus-Magnus-Gymnasium, 1988, p. 224. 
A juzgar por la anotación, es posible que la música de Victoria se contara entre el repertorio interpretado en la época fundacional de la institución. Una segunda anotación, "Joh[annes] Seülinus Cantor 1645”, indica que unas décadas más tarde el libro había cambiado de manos. Johann Reinhard Seulin ocupó el cargo de cantor en el Gymnasium poeticum de Regensburg entre 1634-164974. De confesión evangélica desde 1537-38, esta institución era el centro principal para la formación de los cantores que participaban en las celebraciones religiosas patrocinadas por la municipalidad ${ }^{75}$.

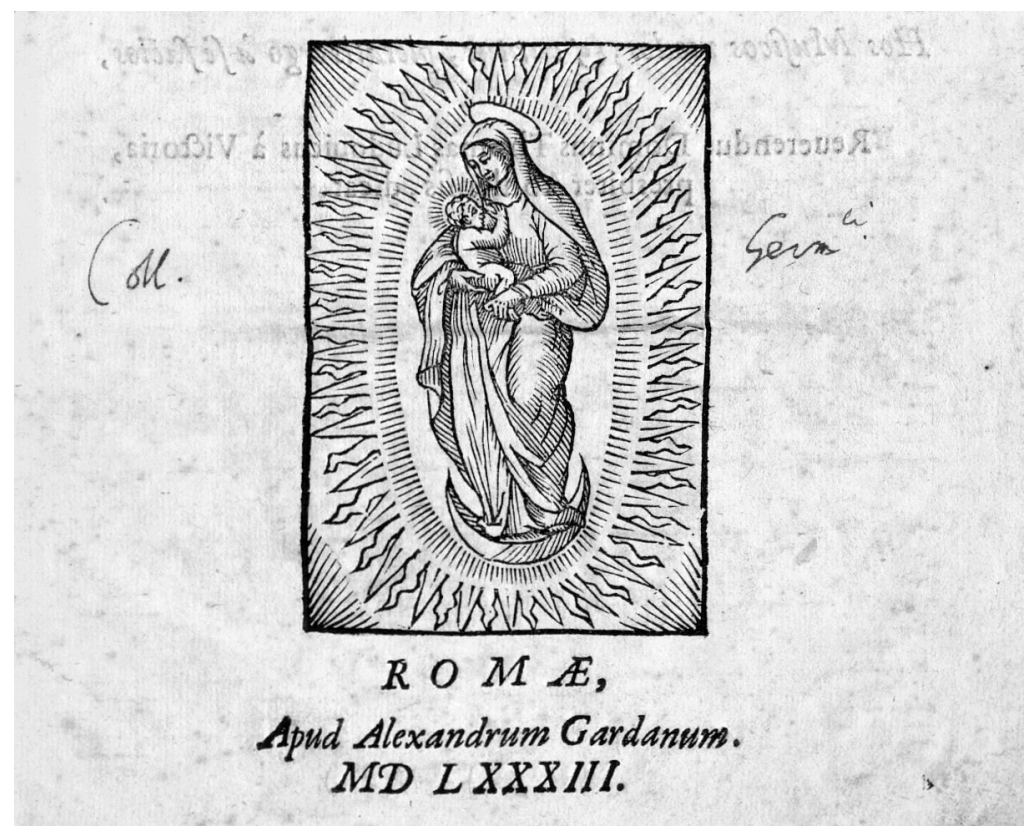

Ilustración 2. Tomás Luis de Victoria: Motecta 1583, voz octava, detalle de la portada (Regensburg, Bischöfliche Zentralbibliothek, BH6226 $6^{76}$ )

\footnotetext{
${ }^{74}$ August Scharnagl: "Zur Musik- und Kulturgeschichte der Stadt Regensburg im 17. Jahrhundert. II. Der Musikunterricht am Gymnasium poeticum. Die Ratsdekrete von 1654 und 1664 zur Pflege des Schulgesangs", Studien zur Musikgeschichte der Stadt Regensburg I, Hermann Beck (ed.), Regensburg, Bosse, 1979 (Regensburger Beiträge zur Musikwissenschaft 6), p. 341.

${ }^{75}$ Un importante número de fuentes procedentes de la institución, también conservadas en la Bischofliche Zentralbibliothek de Regensburg, atestigua la importancia de su vida musical. Gertraut Haberkamp y August Scharnagl (eds.): Sammlung Proske, Manuskripte des 16. und 17. Jahrhunderts aus den Signaturen A.R., B, C, A.N., Múnich, Henle, 1989 (Kataloge Bayerische Musiksammlungen, vol. 14/6), pp. XII-XIII.

${ }^{76}$ Imagen digitalizada y facilitada por la Bischöfliche Zentralbibliothek de Regensburg. Deseo agradecer al Dr. Raymond Dittrich su valiosa ayuda con las fuentes de dicha biblioteca.
} 
La fuente que nos ocupa documenta la recepción de los Motecta de 1583 en instituciones concretas, acercando el repertorio que contiene al ámbito de la práctica. Es especialmente interesante que una de tales instituciones pertenezca a la Compañía de Jesús, candidata, según dicho, a tener en cuenta en aras de reconstruir posibles canales de transmisión de la música del abulense en territorio germánico. El ejemplar de Regensburg confirma además que la circulación de los motetes de Victoria se pudo extender por centros de distintas confesiones, ofreciendo un ejemplo concreto del que parecería el proceso lógico de transmisión: de un centro católico, la fuente pasó a una institución protestante. Lamentablemente, ignoramos dónde adquirieron los jesuitas el libro y, por lo tanto, desde cuándo los Motecta de 1583 circularían por la zona. En otras palabras, la fuente aporta poca información sobre la eventual recepción en la misma de los motetes de Victoria antes de 1589. Cabe la posibilidad de que el ejemplar llegara poco tiempo después de ser publicado. Dos cartas de Victoria de diciembre de 1583, dirigidas al cabildo de la catedral de Jaén y al arzobispo de Milán Carlos Borromeo, respectivamente, sugieren que el compositor, que por entonces residía en Roma, llevó a cabo una campaña de promoción y distribución del impreso ${ }^{77}$. En ellas ofrece la colección a los destinatarios en términos muy parecidos. Junto a correspondencia posterior, estas cartas constituyen una prueba del interés de Victoria por hacer llegar sus obras a contextos alejados de su entorno inmediato, por lo que no debemos descartar que el compositor remitiera la fuente de Regensburg a algún centro o personalidad del contexto germánico ${ }^{78}$. Sea como fuere, lo cierto es que no es posible rastrear su paradero antes de 1597. En este sentido, las Cantiones sacrae son relevantes porque permiten adelantar casi una década el termino ante quo de la recepción de los Motecta de 1583, representando el indicio más temprano de la misma hasta ahora identificado.

77 D. V. Filippi: “Carlo Borromeo...”, p. 40. Cartas reproducidas en A. de Vicente: Tomás Luis..., pp. 58-60 y D. V. Filippi: "Carlo Borromeo...", p. 37.

78 Aunque muy posterior y vinculada a circunstancias distintas, merece la pena mencionar una misiva de 1602 dirigida al Archiduque Fernando de Austria (1578-1637), de contenido muy similar a las dos mencionadas pero con las Missae de 1600 por objeto. Esta carta constituye un caso particular, ya que el receptor no es una institución religiosa. En cualquier caso, representa un testimonio del interés de Victoria por hacer llegar su música a regiones allende los Alpes. Carta reproducida en A. de Vicente: Tomás Luis..., pp. 97-98. 


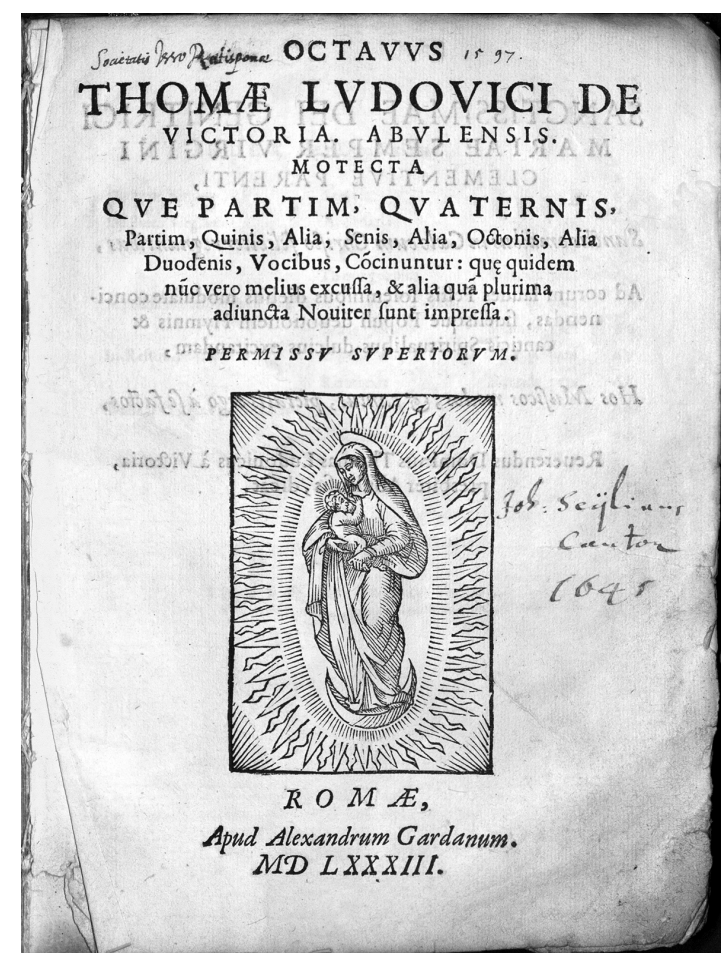

Ilustración 3. Tomás Luis de Victoria: Motecta 1583, voz octava, portada (Regensburg, Bischöfliche Zentralbibliothek, A.R. 47079)

El resultado del examen de las fuentes impresas conservadas es claro: si los motetes de Victoria circularon por territorio germánico antes de 1589, es preciso documentar el fenómeno por otra vía. Afortunadamente, contamos con una fuente manuscrita que enriquece este panorama. Se trata de una colección incompleta de libretes conservada en la Bayerische Staatsbibliothek bajo la signatura Mus. Ms. $1536^{80}$, es la fuente más temprana con música de Victoria conservada en un archivo alemán y, hasta donde sabemos, la única cuya copia podemos situar de forma certera antes de 1589. Aunque incluida hace tiempo en el catálogo de manuscritos que copian música del abulense, hasta la fecha nunca se ha estudiado desde el punto de vista de la recepción.

\footnotetext{
${ }^{79}$ Imagen digitalizada y facilitada por la Bischöfliche Zentralbibliothek de Regensburg.

80 Información y catálogo completo de la fuente en Marie Louise Göllner (ed.): Bayerische Staatsbibliothek: Katalog der Musikhandschriften, 2: Tabulaturen und Stimmbücher bis zur Mitte des 17. Jahrhunderts, Múnich, Henle, 1979 (Kataloge Bayerische Musiksammlungen, vol. 5/2), pp. 101-121. Veáse también Charles Hamm (ed.): Census-Catalogue of Manuscript Sources of Polyphonic Music 1400-1500, Hänssler, Holzgerlingen, 1982, vol. II, pp. 223-224.
} 
Mus. Ms. 1536 es básicamente una antología de motetes, de los que copia más de trescientos. El centenar de autores identificados son de procedencia muy diversa, con predominio de compositores activos en el territorio germánico. Se hallan representadas diversas generaciones, si bien la mayor parte del repertorio fue publicado por primera vez en colecciones impresas de ca. 1550-1580. Victoria está representado con seis atribuciones ${ }^{81}$. Mus. Ms. 1536 es especialmente interesante porque varios de los libretes conservan encuadernaciones originales en las que fueron grabados algunos detalles que permiten determinar de forma fiable la datación y procedencia de la copia: el año 1583, probable fecha de la encuadernación, y las iniciales W[olfgang] N[euhauser] D[ei] G[ratia] P[raepositus] M[onasterii] D[omini] Z[enonis]. Las últimas vinculan la fuente con el monasterio agustino de San Zenón en Bad Reichenhall, al sur de Baviera, aludiendo al que fue el preboste del centro entre 1562-1592, Wolfgang Neuhauser ${ }^{82}$.

En combinación con la información sobre fecha y procedencia, de las características codicológicas de la fuente se derivan datos reveladores. Mus. Ms. 1536 fue copiado por diversas manos, entre las que se distinguen dos principales. La copia de los distintos motetes deVictoria se puede atribuir a una u otra. El repertorio está organizado por número de voces en tres secciones -música a ocho o más voces, a siete y a seis, respectivamente- y, en el librete del Tenor, cada una de las secciones está precedida por un índice que ordena las piezas según el contexto litúrgico. Habida cuenta de que los índices son obra de una única mano, y de que registran prácticamente todo el repertorio incluido en la fuente, es evidente que fueron confeccionados cuando el proceso de copia ya estaba acabado, probablemente en el momento de la encuadernación. Por consiguiente, el año grabado en la portada se erige en un terminus ante quo muy fiable de dicho proceso. El argumento se ve respaldado por la cronología del repertorio: dejando por el momento de lado el caso de Victoria, los impresos más tardíos representados en Mus. Ms. 1536 fechan, precisamente, de 1582-1583. Se trata de los Mottetta typis nondum uspiam excusa de Orlando de Lasso (Múnich, 1582), cuyo contenido íntegro cierra la sección de música a seis voces, y los dos volúmenes de Sacrae modulationes de Vincenzo Ruffo (Brescia, 1583), representados con seis piezas a seis voces y

${ }^{81}$ E. Cramer: Tomás Luis..., p. 96 incluye, erróneamente, otro motete en la lista de piezas atribuidas a Victoria en esta fuente. Se trata de Ego sum panis vivus, en realidad atribuido a Franciscus de Rivulo. El error de Cramer se debe probablemente a que este motete aparece en otras cuatro fuentes atribuido a Victoria (D-Mbs Mus. Ms. 4784, D-Mbs Mus. Ms. 1073, D-Mbs Mus. Ms. 1076 y D-Rp Proske Mappe Victoria I). Sin embargo, todas ellas proceden del siglo XIX, por lo que su atribución se debe, cuanto menos, considerar dudosa.

${ }^{82} \mathrm{El}$ vínculo se ve reforzado por otros detalles, como el que una pieza entre las copiadas por una de las manos principales esté dedicada a Neuhauser, que además incluye referencia al año 1583, o por un motete cuya letra se refiere a San Zenón. 
una a ocho, todas situadas hacia el final de las secciones respectivas. La presencia de las obras de Ruffo, publicadas el mismo año en que presuntamente se encuadernó la fuente, implica un rápido acceso a los impresos por parte de los copistas, suposición que, a juzgar por las características de Mus. Ms. 1536, cuyo contenido sitúa a San Zenón en un contexto de circulación de música de carácter internacional, no resulta problemática.

$\mathrm{Si}$ el terminus ante quo propuesto es acertado, de nuestra fuente se deriva un adelanto de varios años en la recepción de Victoria en territorio germánico respecto a la publicación de las Cantiones sacrae. De nuevo, se nos plantea el interrogante de la transmisión. A excepción del Virgini laudes canimus, un unicum que no figura en ninguna de las colecciones impresas de Victoria, el resto de piezas incluidas en Mus. Ms. 1536 había aparecido en varios impresos antes de $1589^{83}$. Los Motecta de 1572 y 1583 incluyen las cinco, mientras que el Liber primus quo missas... (Venecia, 1576) y los Motecta totius anni (Roma, 1585) recogen tres y cuatro de ellas, respectivamente (Cuadro 3). ¿Representa el manuscrito un testimonio de la recepción de alguna de estas colecciones? Merece la pena detenernos brevemente en la cuestión.

Cuadro 3. Motetes atribuidos a Victoria en D-Mbs Mus. Ms. 1536

\begin{tabular}{|c|c|c|c|c|}
\hline & Motete & Folios (Tenor) & Voces & Publicaciones (hasta 1585$)^{84}$ \\
\hline 1. & Ave maria & $92-92 v$ & 8 & $1572,1576,1583 b, 1585 b$ \\
\hline 2. & Virgini laudes canimus & $92 v-93 v$ & 8 & - \\
\hline 3. & Benedicta sit sancta Trinitas & $317 v-318$ & 6 & $1572,1583 b, 1585 b$ \\
\hline 4. & O sacrum convivium & $318-318 v$ & 6 & $1572,1576,1583 b, 1585 b$ \\
\hline 5. & Vadam et circuibo & $336 v-338$ & 6 & $1572,1583 b$ \\
\hline 6. & Vidi speciosam & $338-339 v$ & 6 & $1572,1576,1583 b, 1585 b$ \\
\hline
\end{tabular}

Como en el caso de los tres motetes atribuidos aVictoria en el Ordo de Hof pero nunca recogidos en uno de sus impresos, aceptar como válida la atribución del Virgini laudes canimus implica suponer algún tipo de transmisión manuscrita que se remontaría hasta el propio compositor. La idea plantea interesantes interrogantes que, por el momento, deberán quedar en el tintero. Al margen de cual fuera el modelo directo de los copistas de San Zenón, el estudio de las variantes permite identificar una filiación para el resto de piezas de Victoria copiadas en Mus. Ms. 1536. Como ya mencionamos,Victoria introdujo repetidamente ligeras modificaciones en las sucesivas ediciones de sus motetes. Pues bien, la comparación entre el contenido de nuestro manuscrito con la historia de dichas variantes revela un contacto con el impreso de

\footnotetext{
${ }^{83}$ Para la atribución del Virgini laudes canimus, E. Cramer: Tomás Luis..., p. 101.

${ }^{84}$ Motecta (Venecia, 1572) [=1572], Missarum liber primus (Roma, 1576) [=1576], Motecta (Roma, 1583) [=1583b], Motecta festorum totius anni [=1585b].
} 
1572, o bien con una tradición manuscrita que tuvo en el mismo su fuente original. De la presencia en Mus. Ms. 1536 de la segunda parte del motete Vidi speciosam se colige que la edición de 1576 no pudo ser el único modelo, ya que en esta colección dicha parte no aparece. La filiación respecto a los impresos de 1583 y 1585 queda asimismo descartada por diversas variantes, de las que hallamos un caso especialmente ilustrativo en el Tenor I del Ave Maria:la forma melódica que presentan las dos últimas breves de esta voz en Mus. Ms. 1536 es concordante con las colecciones de 1572 y 1576 pero difiere de la versión de las dos ediciones posteriores (Ejemplo 1) ${ }^{85}$.

Motecta 1572, D-Mbs Mus. Ms. 1536

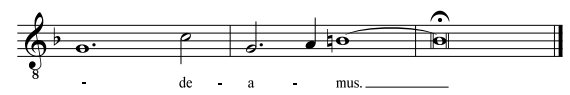

Motecta 1583 y 1585

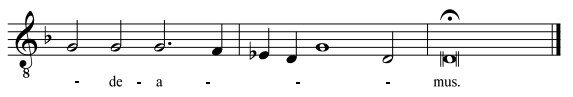

Ejemplo 1. Variante melódica del Ave Maria de Victoria (final Tenor I)

De esta filiación se deriva un dato del mayor interés. Es razonable creer que la vinculación entre Truchsess y Victoria que revela la dedicatoria del impreso de 1572 incidiera favorablemente en la recepción de la música del compositor en territorio germánico. Y cabe suponer que la dedicatoria tuviera como consecuencia la llegada al norte de los Alpes de algún ejemplar de la publicación, hipótesis a la que, como mencionamos al tratar el ceremonial de Hof, apuntan algunos indicios. Pero lo cierto es que no se conserva una sola copia del impreso que respalde de forma positiva el argumento y tampoco contamos con documentación que demuestre que el compositor remitió el libro al dedicatario o que indique que Truchsess se interesó por el mismo. Por su lado, la fuente de Múnich demuestra la recepción de una parte de la colección, o al menos la existencia de una transmisión manuscrita vinculada a la misma, dejando una puerta abierta a la lógica posibilidad de que el impreso de 1572 alcanzara suelo alemán.

El corolario principal de Mus. Ms. 1536 es adelantar la recepción de los motetes de Victoria en territorio germánico hasta principios de la década de 1580. Lamentablemente, se trata de un testimonio aislado que no permite más que especular acerca de las características o extensión del proceso. En este sentido, el escenario que resulta de nuestro estudio es enigmático. Una única fuente documenta la presencia de los motetes del abulense en dicho territorio hacia 1583, como muy tarde, mientras dos testimonios pocos años más tardíos indican una presencia significativa del mismo

${ }^{85}$ La versión de D-Mbs Mus. Ms. 1536 se puede consultar en http://daten.digitale-sammlungen.de/ db/0008/bsb00080189/images/index.html?id=00080189\&fip=eayaewqsdasyztsfsdreayaenewqeayasdase aya\&no=19\&seite=1008, (última consulta: 29-10-2015). 
repertorio, planteando interrogantes que parecen hallar su explicación en la existencia de un fenómeno de circulación anterior, por reducido que fuera. Es tentador, y ciertamente lógico, ver en estos testimonios tres signos del mismo fenómeno, pero por ahora disponemos de escasos indicios que respalden positivamente la suposición.

Esta última cuestión viene a unirse a los numerosos interrogantes planteados, que posiblemente superen en volumen al de las correspondientes respuestas. En cualquier caso, unas y otras deberían contribuir a encauzar futuras pesquisas en la dirección adecuada.Adviértase que se ha intentado mantener un compromiso entre el ejercicio interrogativo y la provisión de evidencias, razón por la que ciertos aspectos no han sido ni siquiera mencionados. Ilustra esta cuestión lo referido a la geografia del fenómeno de circulación abordado. Las fuentes que hemos presentado indican que la zona sur del territorio germánico, y en especial el contexto bávaro, fue una región importante en el proceso de recepción de la música de Victoria. Sin embargo, toda valoración sobre el particular es prematura: solo el buen conocimiento de las fuentes -la suma de estudios que, abarcando un marco cronológico más amplio, se acerquen a ellas de forma individualizada-, la búsqueda documental, y quizás un estudio sistemático de los inventarios conservados, habrán de permitirnos trazar un esbozo mínimamente veraz del proceso.

Además del componente geográfico, otros muchos aspectos relativos a la circulación de la música de Victoria en territorio germánico están pendientes de recibir atención adecuada. Aspectos dotados de indiscutible interés, pero que quedan fuera del objeto de nuestra aportación, cuyo único propósito es contribuir a contextualizar y conocer mejor las fuentes que documentan dicha presencia. Al margen de enriquecer el estado de la cuestión, las observaciones que se derivan del estudio de las Cantiones sacrae, el ceremonial de Hof y las fuentes prácticas deberían servir también para avalar el interés histórico del caso. Un interés que nos remite a la necesidad de atender a ámbitos distintos al italiano e hispánico en aras de completar nuestro conocimiento de la figura deVictoria y la recepción de su música. $\mathrm{Al}$ parecer, el maestro abulense nunca estuvo activo en el territorio germánico y puede que ni siquiera pusiera un pie en él. Tal como sus motetes superaron fronteras geográficas y confesionales, no obstante, conviene vencer los límites de un enfoque historiográfico que, heredero de la preeminencia decimonónica del concepto de autor, siga perpetuando la preeminencia del componente biográfico. El elemento principal que hace del compositor un preciado objeto de estudio es su música y debemos seguirla hasta donde quiera que fue interpretada. 